\title{
Decarbonisation and wholesale electricity market design
}

In recent decades, many power systems have introduced electricity generator competition. Market designs have varied with some countries adopting 'energy-only' markets and others utilising capacity remuneration mechanisms. With increasing deployment of cost competitive renewable energy and the introduction of policy measures to reduce greenhouse gas emissions, concerns are emerging about the sustainability of these market designs. In Australia, wholesale electricity prices have increased markedly - the result of a 'disorderly' transition away from coal to new renewable energy. This paper critically examines the 'energy-only' market in a high penetration renewables system, with a particular focus on the vertically and horizontally restructured National Electricity Market (NEM). We propose that the 'energy-only' market can indeed work within a decarbonised energy system. But as renewables increasingly replace coal-fired power stations, 'unintended consequences' will need to be corrected for to facilitate an 'orderly' transition. It will be important that policy ensures appropriate new investment in firm capacity is forthcoming; and pricing outcomes are acceptable given political economy constraints.

Keywords: climate change; renewables; energy-only markets; market design JEL Codes: D04, D47, Q40, Q41, Q48

\section{Introduction}

The electricity industry has historically had three supply chain components: generation; transmission and distribution; and retail supply (i.e. risk management, marketing, customer services and billing). The role of the wholesale generation market is to enable trading between generators, retailers and other financial intermediaries for short-term delivery of electricity (spot price) and future delivery periods (forward price) (Deng et al., 2001).

There is emerging discussion about whether restructured wholesale energy markets are 'broken' (Keay, 2016). At the core of the discussion is the collision of climate change and renewable energy policies with electricity market operation and design (Nelson et al, 2015). Resolving this 'collision' will be critical given the significant emission reduction commitments made by nations 
at the $21^{\text {st }}$ Conference of the Parties (COP) meeting of the United Nations Framework Convention on Climate Change (UNFCCC).

During deregulation and privatisation processes, inadequate attention was paid to the suitability of market design for achieving multiple policy objectives including reduced greenhouse gas emissions and (in some markets) social equity. Pollitt and Haney (2013, p. 9) state that when energy markets were liberalised, 'competitiveness was the overriding priority. Today, competitiveness, energy security and decarbonisation are the three main energy policy priorities'. It is also arguable that policy makers did not anticipate the significant reduction in the cost of 
renewable technologies observable over the past few years. Nelson (2018) notes that in the Australian context some technologies have fallen in cost by up to $80 \%{ }^{1}$

It is arguable that Australia's 'energy-only' National Electricity Market (NEM) is at the vanguard of considering how best to design energy markets to achieve multiple policy objectives.

Wholesale prices have increased markedly as over $5 \mathrm{GW}$ of coal-fired generation capacity has been retired and new renewable energy has taken its place. Australia has some of the highest rates of embedded solar PV installations in the world. Furthermore, the South Australian region of the NEM has some of the highest penetrations of non-hydro renewables of any electricity market. The region has a peak demand of around 3,500 MW and installed wind capacity is approximately 1,500 MW. The Australian Energy Market Operator (AEMO) estimates that only $10 \%$ of wind capacity and $31 \%$ of solar capacity in South Australia can be relied upon at times of peak summer electricity demand (Nelson and Orton, 2016). Therefore, there is a need for other 'firm' capacity to be available to meet demand when wind and solar PV are unavailable.

As a consequence of a blackout in South Australia in 2016, the Commonwealth Government commissioned a review of Australia's energy markets by a panel of experts chaired by the Australian Chief Scientist (Finkel Review). The Finkel Review (2017) made 50 recommendations aimed at allowing Australia's electricity system to be progressively decarbonised while ensuring security of energy supply and at the lowest possible cost to society. Two key recommendations are considered in this article: the requirement for large generators to provide notice before they permanently close and are decommissioned; and the introduction of some form of generator reliability obligation.

\footnotetext{
${ }^{1}$ Nelson (2018) makes the observation that underlying market dynamics such as declining energy demand make renewable energy the most economic form of investment to supply energy. Other technologies are better suited to supplying firm capacity such as battery storage, pumped hydro and gas-fired generation. 
The broader purpose of this article is to assess whether an 'energy-only' wholesale electricity market design can deliver a largely decarbonised/renewable energy system, with a particular focus on Australia's NEM as it transitions away from conventional coal-fired power stations to a mix of renewables, gas-fired generation and energy storage. The article is structured as follows: Section 2 documents a brief overview of the literature and insights revealed from international experience; Section 3 outlines a theoretical investigation of how 'energy-only' markets respond when other policy instruments are used to drive investment in new generation capacity; empirical observations and modelling results of Australia's electricity system are presented in Section 4; with policy recommendations and concluding remarks provided in Section 5 and 6 respectively. 


\section{An overview of market design with focus on restructured 'energy-only' markets}

The International Energy Agency (2016) provides a useful taxonomy for considering the different temporal aspects of market design. Wholesale electricity markets are often considered in three temporal durations: short-term (minutes to hours); medium term (months to three years); and long-term investment (three to twenty-five years). These are presented in Table 1.

In our view, the major point of difference between market designs is the way in which fixed generation costs are recovered. In 'energy-only' markets, energy is remunerated via dayahead/real time pricing but capacity is not. 'Energy + capacity' markets provide revenue to generators for both the energy they generate and the capacity they make available. Other minor differences include the existence of reserve generator markets and ancillary and operating reserves markets.

Assuming the decarbonisation imperative as a given and drawing upon the taxonomy in IEA (2016), we have established four policy objectives to assess the suitability of wholesale market design: allocative efficiency for dispatching existing generators; ensuring necessary new investment; reliability and security; and maintenance of realistic electricity pricing in the context 
of political economy. For the purposes of this article, it is assumed that increasing penetrations of renewable energy will be deployed to achieve climate change related policy objectives. ${ }^{2}$

Allocative Efficiency for Dispatching Existing Generators

In energy markets, generators receive payments for their energy but not their available capacity or reliability. Schweppe et al. (1988) first demonstrated that competitive spot electricity markets are useful for matching supply and demand. When total capacity exceeds demand, prices are likely to be reflective of just below the short-run marginal cost (SRMC) of the marginal non-dispatched generator in the bid stack. When demand is met with the highest-cost final marginal unit, prices exceed SRMC outcomes, thereby allowing generators to recover their heavy fixed costs. In theory, this also facilitates new investment by providing pricing signals for additional capacity requirements. ${ }^{3}$

A critical shortcoming of energy markets in a 'high penetration' renewables system is the interaction with forward derivative markets. In 'restructured' markets with retail competition, a liquid forward market is critical to facilitate price risk mitigation. As an intermittent energy source, renewables (ex-hydro) are unable to sell financial derivative products to retailers (e.g.

\footnotetext{
${ }^{2}$ We are agnostic in this article about the type of climate change policy mechanism to be used. As Section 4 in this article reveals, modelling of a 'least-cost' approach to climate change mitigation in Australia reveals significant deployment of renewable energy.

${ }^{3}$ There are very specific differences in the way in which energy markets have been structured. Some markets utilise 'regional' prices while others price energy at specific locations through nodal pricing. The auction design is also important with some markets utilising pay-as-bid and others utilising uniform pricing structures. For the purposes of this article, we are focused on the structure of the NEM - an energy-only gross pool electricity market in which prices are formed under a uniform first-price auction clearing mechanism. 
baseload swaps and peak cap contracts). As renewable grid penetration increases, an increasing proportion of the load is traded without price risk mitigation products in place.

\section{Ensuring Necessary New Investment}

There are three main ways in which new investment has traditionally been facilitated: fixed cost recovery through regulated utility rates (in non-restructured retail markets); the use of capacity payment mechanisms; and reliance upon a smaller number of higher price events within restructured 'energy-only' markets such as the NEM. The IEA (2016, p. 13) has stated that, '..most restructured electricity markets include some type of capacity mechanism to ensure resource adequacy in the longer run'. Even with capacity markets in place, investment is increasingly driven by subsidies and other non-market instruments (e.g. renewable portfolio standards). The IEA (2016, p. 12) has concluded that, 'Energy market revenues alone, however, are not enough to attract low-carbon investment at the required scale, in a timely manner and at low cost.' In Australia, Nelson et al (2015) argue that almost all of the new investment since 2002 has been influenced by non-energy market policies.

There is already significant literature on the limitations of 'energy-only' markets for facilitating new investment with identified problems being: regulatory interference; financial market considerations; and market price-caps (see Simshauser, 2008; Simshauser, 2010; Nelson and Simshauser, 2013; Simshauser \& Ariyaratnam, 2014; and Simshauser, 2014). Policy uncertainty has also been problematic (Nelson et al, 2010). The use of price regulation to artificially constrain prices within 'energy-only' markets limit their effectiveness in incentivising new investment. (Besser et al, 2002; Oren, 2003; de Vries, 2003; Wen et al, 2004; Finon and Pignon, 2008; Joskow, 2008; and Simshauser, 2010). The theory of 'energy-only' markets also collides with the real-world incorporation of new investment debt financing of significant sunk capital costs (Peluchon, 2003; Joskow, 2006; Finon, 2008; Simshauser, 2008; Caplan, 2012; Nelson and 
Simshauser, 2013; and Simshauser and Ariyaratnam, 2014). Some energy economists have subsequently concluded that 'energy-only' markets are at risk of producing inadequate revenues to support continued investment in a 'least-cost plant mix' - also known as the 'missing money' problem (Bidwell and Henney, 2004; Neuhoff et al, 2004; Bushnell, 2011; Joskow, 2008; Simshauser, 2008; and Finon, 2008).

In other markets, new mechanisms are being introduced to overcome perceived limitations of energy markets for incentivising new investment. ${ }^{5}$ The UK has recently created a capacity auction to address the need for capacity reserve given renewable intermittency and impending generator retirements, driven at least in part by climate change policy objectives. Ireland is also utilising Reliability Options (ROs) with a similar intent (Newbery, 2016 ${ }^{6} .^{7}$ These developments have implications for pricing in energy markets. Nelson et al (2015, p. 26) state, 'The presence of additional capacity depresses expected future prices despite not physically generating electricity because the broader markets know that capacity can, and will, be recalled above a certain price threshold'.

\section{Reliability and Security}

Reliability and security are often used interchangeably within commentary about power markets. In this article, reliability is limited to the 'reliability of the power generation and transmission assets'. A power system is defined as secure '..when technical parameters such as power flows, voltage, and frequency are maintained within defined limits' (AEMC, 2016, p. i). Market design must incorporate elements that deal to both the reliability and security of the power system.

\footnotetext{
${ }^{5}$ For example, policy makers in Alberta are introducing a capacity market but have also announced caps on tariffs.

${ }^{6}$ Newbery (2016, p. 10) states that, 'The amount of capacity to procure is set by the Government, on the advice of the System Operator, National Grid, and depends on the reliability standard (the Loss of Load Expectation, LoLE, of 3 hours per year), the Value of Lost Load, VoLL, $(£ 17 / \mathrm{kWh})$, which together give a prediction of the gross Cost of New Entry $(\mathrm{CoNE})$ : CoNE $=$ VoLL*LoLE.' ${ }^{7}$ The UK capacity market has facilitated new technologies such as battery storage (see https://www.centrica.com/news/capacitymarket-auction-success-centrica-0, as an example).
} 
Importantly, both thermal and renewable generators (such as wind and solar) can be integrated in ways that provide reliability and security services. For example, the Californian market operator (CAL-ISO) worked with First Solar and NREL to demonstrate that a 300 MW solar PV plant could provide ramping, voltage and frequency services equal to (or in some cases exceeding) those of traditional thermal or hydro plants. Table 2 provides a summary of some of the services that market operators may try to procure.

Reliability of existing plant in an 'energy-only' market is encouraged through a liquid forward contract market that incentivises generators to spend requisite amounts on maintenance. This may be problematic in an environment of flat (or declining) demand and increased renewable penetration, driven by out-of-market climate change policies (see Nelson et al, 2015, for a partial assessment of this issue) as revenues may be insufficient to cover essential maintenance activities. In non-restructured retail markets, any 'missing money' is able to be recovered from regulated consumer electricity rates. This allows maintenance spending to be recovered and reliability to be facilitated. ${ }^{9}$. In other 'energy-only' markets, system resilience and reliability is procured through reserve generator mechanisms. For example, the Electric Reliability Council of Texas (ERCOT) conducts a process for 'reserve (non-spinning) generation' that would be sufficient to replace one of the largest units (should it fail) within 30 minutes (ERCOT, 2013; Garrison, 2014).

Maintenance of realistic electricity pricing in the context of political economy

A key criterion for assessing market design that is often overlooked in our view is the achievement of relatively stable pricing. Electricity systems are complex cultural institutions and

\footnotetext{
${ }^{9}$ See State of New York Public Service Commission (2016) for an example of how heavy fixed costs of nuclear power stations are recovered through rates to ensure ongoing operation and reliability.
} 
consumers expect that prices for a relatively homogenous product delivered by monopolistic infrastructure (i.e. poles and wires) will be stable. 'Energy + capacity' markets involve lower market price caps and associated pricing volatility. 'Energy-only' markets on the other hand produce significant volatility.

Section 3 examines how this criterion is likely to be unmet in an 'energy-only' market, such as Australia's NEM, where demand is flat (or declining) and additional supply is being induced by climate change policy intervention. Both intra-period (NEM spot) and inter-period (forward underlying flat contract) pricing is likely to be affected, and without some adjustment to policy settings, may produce regulatory intervention. The IEA (2016, p. 13) notes that in 'energy-only' markets, 'prices during hours of capacity shortage cannot be free from regulatory interventions. Situations of system stress are rare, and market participants often fail to anticipate them.

Furthermore, generators enjoy market power during these hours, and, as policy makers usually do not tolerate price spikes, price caps have been set too low in many jurisdictions compared to the level needed to meet high reliability standards'.

\section{A theoretical investigation of 'energy-only' markets}

Consider a closed power system within a discrete time period of several years ${ }^{10}$ where each demand level is presented from minimum demand $\left(D_{1}\right)$ to peak demand $\left(D_{X}\right)$. 'Average' demand, which occurs for the greatest amount of time, would sit somewhere between these points. Within this system, a discrete number of generators $\left(\mathrm{G}_{1}\right.$ to $\left.\mathrm{G}_{\mathrm{Y}}\right)$ of varying capacities are available to meet demand and are presented from lowest short-run marginal cost (SRMC) to highest SRMC. As we

\footnotetext{
${ }^{10}$ Our focus is on inter-period pricing in this model. Our primary area of research focus is the shifting of underlying derivative contract pricing between two time periods of several years. Within a specific time period (i.e. intra-period) pricing will continue to be volatile, reflecting the seasonal and diurnal nature of electricity demand.
} 
are examining an 'energy-only' market, costs are per unit of energy produced. This system is shown in Figure 1.

Each generator has a distinct Long-run average cost (LRAC) shown in Equation 1.

$L R A C_{G}=\left(T E_{S O} * F C\right)+V O M+F O M+R_{e}+R_{d}$

(Eq. 1)

The LRAC of each power station is a function of: short-run marginal costs which are incurred each time the power station generates - the cost of fuel (FC) multiplied by the sent-out thermal efficiency of (TESO) and the variable operating and maintenance costs (VOM); and fixed costs permanent longer-term operating and maintenance costs (FOM), and equity and debt costs $\left(\mathrm{R}_{\mathrm{e}}\right.$ and $R_{d}$ respectively). ${ }^{12}$ While equity and debt costs are not 'fixed', they do represent upfront fixed costs of building the power station. If they are not recovered, investors are unlikely to invest

\footnotetext{
${ }^{12}$ For simplicity, we have assumed a zero tax rate. We do not anticipate that taxation treatment would materially impact on our analysis. 
further in generation in the discrete system. We can simplify Equation 1 into short-run and longrun costs accordingly where ROC includes equity and debt.

$L R A C_{G}=S R M C+F O M+R O C$

Over the business cycle, an ‘energy-only' market with an 'optimal mix of generation' should ensure that the sum of all generator costs are recovered. ${ }^{13}$ This is shown in Equation 3 where $\mathrm{P}$ is the price in each discrete period and $\mathrm{D}$ is the demand.

$\sum_{i=1}^{Y}{ }^{\prime} R A C_{G_{i}}=\sum_{i=1}^{X}\left(P_{i} * D_{i}\right)$

Where generation capacity significantly exceeds demand, prices trend towards SRMC. During these periods FOM and ROC costs are not recovered. But where demand is very high relative to

13 The theoretical example in this section is based upon a simple market model. It may be impacted by the existence of integrated retailer/generation portfolios and whether the retail market is restructured (or not), among other things. Critical potential issues such as ensuring sufficient competition and potential barriers to entry are being examined by the Australian Competition and Consumer Commission (ACCC) in a specific inquiry into the electricity industry commissioned by the Commonwealth Government in 2017. 
installed capacity, prices must exceed the SRMC of the marginal generator (mg) to ensure that such costs are recovered. This is shown as a general theorem in Equation 4.

if $D\left\{\begin{array}{l}\ll D_{X}, P \sim S R M C_{m g} \\ \cong D_{X} P \sim S R M C_{m g}+\beta\end{array}\right.$

Firms operating in this market will have a high number of 'average demand' periods where only short-run costs are recovered and a small number of 'peak demand' $\left(D_{X}\right)$ periods where significant 'super profits' are earned. These 'peak demand' periods are generally assumed to be the way in which FOM and ROC can be recovered through $\beta$. The average price across the business cycle cannot be significantly higher than the outcome presented in Equation 4 in the long-run. If the average price exceeds this consistently over a period of time, it will result in new entrants and prices will not facilitate total FOM and ROC recovery until demand equals or exceeds the new level of capacity.

But in an environment where demand is not growing and supply is being added through renewable energy policies (e.g. feed-in tariffs, contracts for difference and the like) there may be implications for reliability and security of supply. Let us consider a two-period scenario where renewable energy is added to the closed system and its capacity 'de-rated' so that only the energy that is 'firm' is included. The first period is shown in Figure 2.

In this first period $(\mathrm{t}=1)$, there is less demand relative to capacity. As such, prices are unlikely to exceed the $\mathrm{SRMC}$ of the marginal generator required to meet $\mathrm{D}_{\mathrm{X}}\left(\mathrm{SRMC}_{\mathrm{mg}}\right)$ and such pricing outcomes will persist for a prolonged period of time. The rational participant will mothball units where pricing does not exceed the individual generator's SRMC in the short-term. The pricing 
outcomes in this period will be almost entirely consistent with the first state outlined in Equation 4.

Within the discrete time period, such pricing outcomes will result in revenues from the wholesale market being inadequate to recover all of the FOM and ROC costs of each generator with recovery of these costs trending to zero for the marginal generator and the FOM and ROC of other dispatched generators being potentially inadequate. Eventually, the inadequate spending on FOM may result in sufficient generation failing so that total installed capacity equals $\mathrm{D}_{\mathrm{X}}$. However, this may present temporal issues whereby generation fails or is permanently closed at a rate greater than anticipated and installed capacity falls below $\mathrm{D}_{\mathrm{x}}$. Operating generating units declines from $\mathrm{G}_{\mathrm{Y}}$ to $\mathrm{G}_{\mathrm{Y}-\mathrm{Z}}$ where $\mathrm{Z}$ equals the number of units that 'drop out' of the supply stack. This is entirely possible given the long lead times required to build new firm capacity. ${ }^{15}$ In the second time period $(\mathrm{t}=2)$, most pricing events would shift towards the second state of Equation 4.In other words, prices would rise substantially

In the scenario described above, there would be prolonged periods of low pricing followed by periods of much higher prices. However, it may be difficult to determine ex ante when conditions would result in the system shifting between the two pricing outcomes. A key assumption in this analysis relates to the inability of producers to determine when other power stations will be permanently closed. This is explored in practice in the subsequent section. Mothballing provides

\footnotetext{
${ }^{15}$ Constructing a power station requires several years lead times for: planning approval; environmental statements; fuel contract negotiations; engineering procurement (EPC); haulage and transmission negotiations; and actual construction. 
optionality for producers but the presence of the unit keeps prices low given it can be recalled at short notice (see Nelson et al, 2015). This exacerbates the situation described above.

Our model is similar to 'cobweb' models that consider time lags between supply and demand decisions (first developed by Ezekiel, 1938). To date, the application of 'cobweb' models in electricity markets has largely been focused on intra-period pricing (see Cavalli et al, 2015; and Contreras et al, 2001). Our focus on inter-period pricing relies heavily on the assumption that producers cannot learn from previous experience about when a power station may close within a time period that allows new firm capacity to be constructed. Given the lumpy nature of capital investment within electricity markets, it may be difficult for expectations to adapt sufficiently to overcome this problem.

Our analysis suggests violation of at least two of the criteria established for assessing energy market effectiveness in Section 2: reliability and security; and maintenance of realistic political economy of electricity pricing. 'Energy-only' markets generally involve price fluctuations that represent growing demand and the diurnal/seasonal nature of electricity demand, not prolonged low and then high forward contract pricing events created by renewable energy investment policies implemented outside the 'energy-only' market. ${ }^{16}$ A question for policy makers therefore relates to how it is possible to ensure that the distribution of $\beta$ across time better reflects the fundamentals of 'energy-only' market design.

\subsection{Inter-period pricing}

Figure 3a shows a stylised shift in forward contract pricing trends associated with the introduction of renewables and other policies that drive investment in new generation capacity,

\footnotetext{
${ }^{16}$ This analysis builds upon Nelson et al (2015) who discussed how renewable energy policies result in inadequate revenues for individual generators in energy-only markets. 
irrespective of whether demand requires it. The chart on the left shows an 'energy-only' market without the overlay of other policy interventions. Forward contract prices rise and fall based upon tightening reserve margins due to increasing demand driving up prices or excess capacity driving up reserve margins respectively. The chart on the right shows how price trends shift in an 'energy-only' market with subsidised renewables. Prices fall to very low levels due to oversupply and low-SRMC renewable generation. Firm thermal generators cannot recover FOM and eventually are removed in a 'disorderly' way, potentially resulting in sustained periods of above LRAC pricing.

\subsection{Intra-period pricing}

Figure $3 \mathrm{~b}$ shows the stylised impacts of increased renewable penetration on intra-period spot pricing. ${ }^{18}$ As renewables enter the market, they occupy the bottom of the merit-order bid stack and at times of coincident dispatch that exceeds demand are priced at SRMC (i.e. effectively zero). For other generators to recover their heavy fixed costs over the business cycle, prices at other times must increase significantly. Within Australia, estimates have been made in relation to how high the market price cap would need to be for generators to recover their long-run costs in a high-penetration renewable scenario. Riesz et al (2016) concluded an increase from $\$ 13,100$ per MWh to between $\$ 60,000$ and $\$ 80,000$ per MWh would be necessary although high price events would not necessarily be occurring frequently. In itself, this is not necessarily an issue but, as noted in Section 2, it is important to think through how a restructured retail market would

\footnotetext{
${ }^{18}$ Intra-period pricing may also be impacted by the choice of climate change policy. For example, in a system with most generators benefiting from Contracts for Difference (CfDs), generators with the highest CfDs will be able to produce at lower prices than those with a lower CfDs. Effectively, the bias is towards the more expensive plants. The impacts of specific climate policy design on energy-markets is therefore worthy of further research. 
function in this environment given the reduced availability of traditional financial derivative products.

\section{Empirical observations and modelling of the Australian NEM}

As noted earlier in this article, Australia is arguably one of the best markets to assess the impact of renewables and climate change policy on energy-market design. South Australia has one of the highest penetrations of intermittent or variable renewable energy of any region in the world. ${ }^{19}$ Furthermore, renewables are more economic than gas-fired power generation for providing energy due to chronic domestic gas supply unavailability. ${ }^{20}$ Unsurprisingly, government policy is skewed towards supporting renewable investment as a method of reducing emissions. The Victorian and Queensland governments have established policies to achieve $40 \%$ and $50 \%$ renewable energy penetration by 2025 and 2030 respectively. These targets are likely to drive abatement towards partially achieving Australia's COP21 commitment to reduce emissions by $26-28 \%$ on 2005 levels by 2030 .

Simshauser (2014) demonstrates that the NEM has been an efficient engine for dispatch (the first assessment criterion in Section 2) but has not produced pricing outcomes sufficient to incentivise new investment (the second assessment criterion in Section 2). However, pricing has increased substantially since 2015. Significant withdrawals of aged thermal plant has led to tightening reserve margins and warnings of potential reliability standard breaches. Average prices in 2017 reflect both a resurgence in peak demand and a tighter demand/supply balance. Figure 4 shows

\footnotetext{
${ }^{19}$ Australia's Clean Energy Council (2017, p. 9) has estimated that $48 \%$ of electricity in South Australia was produced by renewable energy (wind and solar) in 2016.

${ }^{20}$ While east-coast Australia has significant gas reserves, the vast majority of $2 \mathrm{P}$ reserves are now allocated for export through a new LNG export industry in Gladstone, Queensland. Simshauser and Nelson (2015) provide a detailed explanation of the events that led to this situation. 
forward pricing in Victoria and the increases attributable to the permanent retirement of the 1,600 MW coal-fired baseload Hazelwood power station in March 2017. ${ }^{22}$

Figure 4 effectively demonstrates the inter-period pricing phenomenon established in Section 3. Prices were significantly below LRAC for many years due to oversupply created by flat underlying energy demand and additional supply driven by climate change policies. This resulted in economic pressure being placed upon remaining generators which eventually led to the disorderly withdrawal of the Hazelwood power station. Only six months' notice was provided, well below the time required to invest in the requisite new firm capacity. ${ }^{23}$ Increased wholesale pricing has resulted in significant discussion within Australia about electricity prices being 'too high', evidence that the real political economy of energy prices is not necessarily being met by existing ‘energy-only’ market design (the fourth criteria from Section 2). ${ }^{24}$

The same scenario described above occurred in South Australia in 2015/16. In October 2015, the owners of the Northern (546 MW) and Playford (240 MW) power stations announced their permanent closure in May $2016 .{ }^{25}$ Again, with less than a year of notice, there was no time for new generation to be built (see Nelson and Orton, 2016). Capacity is required to complement the significant penetration of wind generation within the South Australian region. However, 'baseload' coal-fired generation is unsuited to these duties. Figure 5 demonstrates that lower capacity factor 'firm' plant (e.g. open-cycle gas turbine: OCGT technology) would be better suited than existing less flexible plant to complement wind generation. Renewables and plant with fast start and ramping capabilities are economic complements, not substitutes. The

\footnotetext{
22 See http://www.gdfsuezau.com/media/UploadedDocuments/News/Hazelwood\%20Clousure/Hazelwood\%20closure\%20\%20Media\%20release.pdf for further information, Accessed online on 17 February 2017.

${ }^{23}$ Note the specific use of the term capacity rather than energy. The market will continue to need capacity to meet peak demand but less thermal energy at non-peak times due to the introduction of intermittent renewables.

${ }^{24}$ A reviewer of this manuscript correctly pointed out that the closure of the Hazelwood (and other power stations) had been discussed by many stakeholders years before it actually closed. Given the lumpy nature of capital investment and issues relating to policy uncertainty, no new investment in firm capacity was forthcoming.

${ }^{25}$ See https://alintaenergy.com.au/about-us/power-generation/flinders-operations for further information. Accessed online on 17 February 2017.
} 
peak/average factor in the South Australian region is 1.89 but if wind is excluded it increases to 2.94. Capacity is required but for much fewer hours of the year. Much of the remaining plant in the South Australian market is unsuited for providing this type of 'flex'.

Wind generation is increasingly reliant upon climate change policy subsidies as it suffers from a 'price penalty' due to its nature as a 'price taker' and coincident generation profile. Figure 6 shows the weighted average spot price in South Australia calculated by technology type. In every year, wind receives less revenue due to its inability to generate at times when energy is most valuable (e.g. peak demand times). It is also unable to forward contract by selling forward derivative products. In our view, these issues will become even more evident as more renewable energy enters the market in coming years to achieve the $26-28 \%$ emissions reduction target established by the Commonwealth Government.

To establish how the market may look in 2030 with a $26-28 \%$ emissions reduction target achieved, we have used a PLEXOS 'least cost' model of the NEM to model such a scenario. ${ }^{26}$ Figure 7 shows the generation output in the NEM with a $27 \%$ emissions reduction target in place. There is a declining role for coal-fired power stations and material investment in renewables. Gas substitution for coal is forecast to play a relatively small role (see earlier Footnote 19). Around 12 GW of new large-scale renewable capacity is required and $11.5 \mathrm{GW}$ of embedded small scale distributed solar PV is installed.

Table 3 shows the ratio between high and low wholesale electricity price periods is projected to increase by a factor of three if the target of $26-28 \%$ of 2005 levels by 2030 is to be achieved. In

${ }^{26}$ See Appendix 1 for further information about the PLEXOS modelling. 
other words, the intra-period pricing volatility discussed in Section 3 is likely to become more extreme. This is consistent with the findings of the study by Riesz et al (2016).

\section{Policy recommendations}

The evidence presented in Section 4 provides support for the theoretical limitations of 'energyonly' markets established in Section 3. As such, it is necessary to consider how policy-makers could best overcome these limitations. Our recommendations flow from assumptions that in the long-term, increased penetration of renewables is likely to be a pre-requisite for addressing anthropogenic climate change. ${ }^{27}$ At a high level, our recommendations are consistent with those made by the Finkel Review.

\section{Addressing inter-period pricing}

Inter-period pricing in 'energy-only' markets is likely to continue to be at odds with the criterion of realistic political economy of energy pricing given our assumption of producer expectations of competitor behaviour in relation to capital injection and withdrawal. Energy consumers are unlikely to be satisfied if prices are subdued for a period of time but then rapidly increase due to the 'lumpy' withdrawal of thermal plant. We contend that an 'orderly' transition to a higherpenetration renewables system can be facilitated within an 'energy-only' market if generators provide sufficient notice of impending closures to allow new complementary capacity to be

\footnotetext{
${ }^{27}$ While Australian climate change policy is currently uncertain, analysis in Section 4 shows that renewables are likely to be required to reduce emissions. 
built. ${ }^{28}$ There are a plethora of ways this 'sufficient notice of closure' could be achieved through either planning laws or amendments to generation registration rules.

\section{Addressing intra-period pricing and facilitating new investment}

In our view, new investment in capacity is likely to be driven by climate change policies that encourage fuel substitution. ${ }^{29}$ However, it is important that this new investment is 'dispatchable' and can actively participate in the market. Active participation facilitates the forward contracting of generation and the operation of a competitive downstream restructured retail market (allowing intra-period pricing volatility to be managed).

Rather than embarking upon a major reform of the electricity market (by, for example, creating a capacity market), it may be preferential for policy makers to slightly alter the design of climate change policies or renewable energy obligations to ensure unintended consequences of climate change policies for 'energy-only' markets are avoided. Intermittent, non-contractible generation (i.e. wind, solar etc) could be required to contract with complementary plant such as OCGT, demand-response, advanced batteries or pumped hydro to create a 'synthetic financial generator', capable of bidding into the spot market and participating in forward derivative markets for some part of their total capacity. This could be achieved through a market mechanism (e.g. 'firm capacity right' certificate which would be required to be stapled to renewable generation facilitating some proportion of the capacity being 'firm') or a generator reliability obligation. This effectively solves (albeit temporarily) the limitations of 'energy-only' markets for incentivising

\footnotetext{
${ }^{28}$ Forward expectations of market participants should theoretically result in new plant being constructed ahead of announced closures as it is total revenues over the life of the project that make it economic, not the cashflow in the first few years. In practice, many renewable energy projects are being project financed and highly geared. This results in a need to generate superior cash flows early in the project life.

${ }^{29}$ This is irrespective of whether a carbon price (e.g. emissions intensity scheme), direct renewable portfolio obligations or contract for difference policies are pursued.
} 
new investment. The combination of renewables and 'stapled' firm plant effectively introduces a 'capacity' market through the climate change policy mechanism.

Alternatively, it may be that a solution could be developed by market participants themselves. At present, there are two key derivative contracts used to mitigate price risks: baseload swap contracts; and peaking cap contracts. A third contract could be developed that integrates non-firm renewables with firm sources to provide an equivalent baseload swap contract. Such a development would be desirable for at least two reasons: it would facilitate retail market innovation and competition by ensuring that sufficient price mitigation hedging tools are available; and it would allow the 'synthetic financial generator' to optimise investment to ensure the right lower capacity factor plant is forthcoming to complement renewables (rather than the sub-optimal use of higher duty incumbent plant that is not suited to such operation). Renewable generators would be better able to participate in the market and be less reliant upon subsidies. There would also potentially be a more transparent 'transfer payment' from non-firm renewable generators to 'firm generators' that provide integration services that are not currently explicitly valued. ${ }^{30}$ At the same time, the market price cap (MCP) would need to be increased, or more controversially removed, to ensure costs can be recovered and market participants are incentivised to hedge pricing risk. It must be emphasised that a higher market price cap may not result in higher pricing volatility. A higher cap would incentivise participants to enter into

\footnotetext{
${ }^{30}$ Markets (such as ancillary services) will allow non-renewable plant to complement intermittent renewable energy. However, we are of the view that our proposed solution would allow for liquid forward markets for baseload and peak pricing, thereby facilitating required new investment. 
financial derivative contracts and deploy storage technologies such as batteries and pumped hydro. These technologies may act to alleviate higher spot pricing volatility.

The expanded role of reliability and security markets

Table 2 is a useful indicator of how reliability and security markets may evolve in Australia. But there is also one further aspect to reliability which is worth reconsidering. At present, it is well known that the existence of operating system reserve supresses pricing signals to incentivise new investment in the wholesale market (see Hogan, 2013, for an analysis of an operating reserve demand curve to overcome this limitation). As noted earlier, this is not necessarily a problem in the short-term if climate change policy correctly incentivises new low-emission plant.

However, it may be worth considering how demand response, storage or surplus plant could be procured to provide system resilience for unforeseen events (e.g. extreme weather related transmission line failure). The ERCOT 'reserve (non-spinning) generation' approach is worth considering as a good example of such procurement, as are the various flexibility services provided by Great Britain's National Grid. It is important that relatively fast-start generation be procured to be 'on standby' to respond to meet demand should an unforeseen event occur. To ensure this procured generator does not impact on the supply/demand balance in the 'energyonly' market, it would be prevented from participating in the energy market. We do not anticipate this to be costly. Brattle Group and Astrape Consulting (2013, p. 51) found that according to 
several quantitative analyses, '..even a several percentage points increase in the target reserve margin would only slightly increase average annual costs'.

A summary of our recommendations to address the policy criteria in Section 2 is presented in Table 4.

\section{Concluding remarks}

This paper has established four criteria for assessing wholesale market design: allocative efficiency for dispatching existing generators; ensuring necessary new investment; reliability and security; and maintenance of realistic electricity pricing in the context of political economy. Our theoretical investigation and empirical analysis (based upon the Australian experience) suggests that with the introduction of climate change policies incentivising the deployment of large volumes of renewable energy and the retirement of conventional coal-fired power stations, intraperiod and inter-period pricing outcomes will not be consistent with meeting these four criteria.

Moving forward, it will be necessary for policy-makers to better integrate climate change and energy policy. Our recommendations involve correcting for the 'unintended consequences' of climate change policy on the operation of energy markets and are broadly consistent with those made by the Finkel Review: the introduction of incentives to ensure that intermittent generation sources become 'firm' and dispatchable; a rule-based mechanism for ensuring advanced warning

of impending 'firm' generator closure; and the use of supplementary markets to improve security, reliability and system resilience. 


\section{References}

Australian Energy Market Commission: AEMC. (2016), 'Interim Report: System Security Market Frameworks Review', AEMC Publication, Sydney.

Besser, J. Farr, J. and Tierney, S. (2002), 'The political economy of long-term generation adequacy: Why an ICAP mechanism is needed as part of standard market design', The Electricity Journal, Vol. 15, pp. 53-62.

Bidwell, M. and Henney, A. (2004), 'Will NETA ensure generation adequacy?', Power UK, No. 122, April.

Brattle Group and Astrape Consulting (2013), 'Resource Adequacy Requirements: Reliability and Economic Implications', Report prepared for FERC, Available at www.ferc.gov/legal/staffreports/2014/02-07-14-consultant-report.pdf, Accessed online on 17 February 2017.

Bushnell, J. (2011), 'Building blocks: Investment in renewable and non-renewable technologies', Energy Institute at Haas Working Paper, No. 202, Berkeley, California.

California Independent System Operator: CAL-ISO. (2016), 'Using renewables to operate a lowcarbon grid', CAL-ISO Publication, Sacramento.

Caplan, E. (2012), 'What drives new generation construction? An analysis of the financial arrangements behind new electric generation projects in 2011', The Electricity Journal, Vol. 25, No. 6, pp. 48-61.

Cavalli, F. Naimzada, A. and Parisio, L. (2015), 'A cobweb model for electricity markets', 2015 12th International Conference on the European Energy Market (EEM), Lisbon, pp. 1-5.

Clean Energy Council. (2017), Clean Energy Australia Report 2016, Clean Energy Council Publication, Melbourne.

Contreras, J. Candiles, O. de la Fuente, J.L and Gomez, T. (2001), 'A Cobweb Bidding Model for Competitive Electricity Markets', IEEE Power Engineering Review, Vol. 21, No. 11, pp. 56-56.

de Vries, L. (2003), 'The instability of energy-only electricity markets', Research Symposium: European Electricity Markets, The Hague, September 2003.

Deng, S.J. Johnson, B. and Sogomonian, A. (2001), 'Exotic electricity options and the valuation of electricity generation and transmission assets', Decision Support Systems, Vol. 30, pp. 383392.

Energy Research Partnership: ERP. (2015), Managing flexibility whilst decarbonising the GB electricity system, ERP Publication.

ERCOT. (2013), ERCOT Methodologies for Determining Ancillary Service Requirements, ERCOT Publication, Austin.

Ezekiel, M. (1938), 'The Cobweb Theorem', The Quarterly Journal of Economics, Vol. 52, No. 2, pp. 255-280. 
Finon, D. (2008), 'Investment risk allocation in decentralised markets: the need of long-term contracts and vertical integration', OPEC Energy Review, Vol.32, No.2, pp. 150-183.

Finon, D. and Pignon, V. (2008), 'Electricity and long-term capacity adequacy: the quest for regulatory mechanisms compatible with electricity markets', Utilities Policy, Vol.16, pp.143-158.

Garrison, J. (2014), ‘A grid-level commitment assessment of high wind penetration and utilisation of compressed air storage in ERCOT', PhD Dissertation, University of Texas.

Hogan, W. (2002), 'Electricity market restructuring: reforms of reforms. Journal of Regulatory Economics', Vol. 21, pp. 103-132.

International Energy Agency: IEA. (2016), Re-powering Markets: Market design and regulation during the transition to low-carbon power systems, IEA Publication, Paris.

Joskow, P. (2006), 'Competitive electricity markets and investment in new generating capacity', AEI-Brookings Joint Centre for Regulatory Studies, Working Paper No.06-14.

Joskow, P. (2008), 'Capacity payments in imperfect electricity markets: need and design', Utilities Policy, Vol.16, pp. 159-170.

Keay, M. (2016), 'Electricity markets are broken - can they be fixed?', Oxford Insitute for Energy Studies Paper, No. EL 17.

Nelson, J. and Simshauser, P. (2013), 'Is the Merchant Power Producer a broken model', Energy Policy, Vol. 53(C), pp. 298-310.

Nelson, T. (2018), 'The future of electricity generation in Australia: A case study of New South Wales', The Electricity Journal, In-press.

Nelson, T. and Orton, F. (2016), 'Climate and electricity policy integration: Is the South Australian electricity market the canary in the coalmine', The Electricity Journal, Vol. 29, No. 4, pp. 1-7.

Nelson, T. Reid, C. and McNeill, J. (2015), 'Energy-only markets and renewable energy targets: complementary policy or policy collision', Economic Analysis and Policy, Vol. 46, pp. 25-42.

Nelson, T., Kelley, S., Orton, F. and Simshauser, P. (2010), 'Delayed carbon policy certainty and electricity prices in Australia', Economic Papers, Vol. 29, No. 4, pp. 446-465.

Neuhoff, K. and De Vries, L. (2004), 'Insufficient incentives for investment in electricity generation', CMI Working Paper 42, Cambridge.

Newbery, D. (2016), 'Tale of two islands - Lessons for EU Energy Policy from Electricity Market Reforms in Britain and Ireland', EPRG Publication, Cambridge.

Newbery, D.M. (2012), 'Reforming Competitive Electricity Markets to Meet Environmental Targets', Economics of Energy and Environmental Policy, Vol. 1, No. 1, pp 69-82.

Oren, S. (2003), 'Ensuring generation adequacy in competitive electricity markets', University of California Energy Institute - Energy Policy \& Economics 007, University of California, Berkley 
Pollitt, M. and Haney, A. (2013), 'Dismantling a competitive retail Electricity Market:

Residential Market Reforms in Great Britain', The Electricity Journal, Vol. 27, No. 1, pp. 66-73.

Riesz, J. Gilmore, J. and MacGill, I. (2016), 'Assessing the viability of Energy-Only Markets with 100\% Renewables', Economics of Energy \& Environmental Policy, Vol. 5, No. 1.

Schweppe, F. Caramanis, M. Tabors, R. and Bohn, R. (1988), Spot pricing of electricity, Kluwer Academic Publishers, London.

Simshauser, P. (2008), 'The Dynamic Efficiency Gains from Introducing Capacity Payments in the National Electricity Market', The Australian Economic Review, Vol. 41, No. 4, pp. 349-70.

Simshauser, P. (2010), 'Vertical integration, credit ratings and retail price settings in energy-only markets: Navigating the Resource Adequacy problem,' Energy Policy, Vol. 38, No. 11, pp. 7427 7441.

Simshauser, P. and Nelson, T. (2015), 'Australia's coal seam gas boom and the liquefied natural gas entry result', Australian Journal of Resource and Agricultural Economics, Vol. 59, No. 4, pp. $1-22$

Simshauser, P. (2014), 'From first place to last: Australia's policy-induced energy market death spiral', Australian Economic Review, Vol. 47, No. 4, pp. 540-562.

Simshauser, P. and Ariyaratnam, J. (2014), 'What is Normal Profit for power generation?', Journal of Financial Economic Policy, Vol. 6, No. 2.

State of New York Public Service Commission. (2016), 'CASE 15-E-0302', New York Public Service Commission Proceeding.

Wen, F. Wu, F. and Ni, Y. (2004), 'Generation capacity adequacy in the competitive electricity market environment', Electrical Power \& Energy Systems, Vol. 26, pp. 365-372.

Wu, F. Zheng, F. and Wen, F. (2006), 'Transmission investment and expansion planning in a restructured electricity market', Energy, Vol. 31, pp. 954-966. 
Page 28 